\title{
Tumour cell lysate-loaded dendritic cell vaccine induces biochemical and memory immune response in castration-resistant prostate cancer patients
}

D Reyes ${ }^{1,2,3}$, L Salazar ${ }^{1,3}$, E Espinoza ${ }^{3}$, C Pereda ${ }^{1,3}$, E Castellón $^{1}$, R Valdevenito ${ }^{2}$, C Huidobro ${ }^{2}$, M Inés Becker ${ }^{4}$, A Lladser ${ }^{5}$, M N López ${ }^{1,3,6}$ and F Salazar-Onfray ${ }^{\star, 1,3}$

${ }^{1}$ Institute of Biomedical Sciences, Faculty of Medicine, University of Chile, Santiago 8380453, Chile; ${ }^{2}$ Service of Urology, University of Chile Clinical Hospital, Santiago 8380453, Chile; ${ }^{3}$ Millennium Institute on Immunology and Immunotherapy, University of Chile, Santiago 8380453 Chile; ${ }^{4}$ Fundación Ciencia y Tecnología para el Desarrollo, Santiago 7750269, Chile; ${ }^{6}$ Cell Therapy Laboratory, Blood Bank Service, University of Chile Clinical Hospital, Santiago 8380453, Chile and ${ }^{5}$ Fundación Ciencia y Vida, Santiago 7780272, Chile

Background: Recently, we produced a tumour antigen-presenting cells (TAPCells) vaccine using a melanoma cell lysate, called TRIMEL, as an antigen source and an activation factor. Tumour antigen-presenting cells induced immunological responses and increased melanoma patient survival. Herein, we investigated the effect of TAPCells loaded with prostate cancer cell lysates $(\mathrm{PCCL}$ ) as an antigen source, and TRIMEL as a dendritic cell (DC) activation factor; which were co-injected with the Concholepas concholepas haemocyanin $(\mathrm{CCH})$ as an adjuvant on castration-resistant prostate cancer (CRPC) patients.

Methods: The lysate mix capacity, for inducing T-cell activation, was analysed by flow cytometry and Elispot. Delayed-type hypersensitivity (DTH) reaction against PCCL, frequency of $\mathrm{CD}^{+}$memory $\mathrm{T}$ cells $(\mathrm{Tm})$ in blood and prostate-specific antigen (PSA) levels in serum were measured in treated patients.

Results: The lysate mix induced functional mature DCs that were capable of activating PCCL-specific T cells. No relevant adverse reactions were observed. Six out of 14 patients showed a significant decrease in levels of PSA. DTH ${ }^{+}$patients showed a prolonged PSA doubling-time after treatment. Expansion of functional central and effector CD8 ${ }^{+} \mathrm{Tm}_{\mathrm{m}}$ were detected.

Conclusion: Treatment of CRPC patients with lysate-loaded TAPCells and CCH as an adjuvant is safe: generating biochemical and memory immune responses. However, the limited number of cases requires confirmation in a phase II clinical trial.

Prostate cancer (PC) is the second leading cause of male tumourrelated deaths in developed countries (Jemal et al, 2009). As of now there is no curative treatment for local-advanced or disseminated PC, and the only available handling is androgen deprivation therapy (ADT; Huggins and Hodges, 2002). Androgen deprivation therapy has showed important short-term effects in diminishing tumour growth, however, a significant percentage of treated patients have developed hormone-independent neoplastic cells; becoming resistant to the treatment and displaying a fast tumour progression (Pienta and Bradley, 2006). Docetaxel-based chemotherapy has showed limited clinical benefits in patients with castration-resistant PC (CRPC); improving in 2 months the patients' overall survival, nevertheless, it shows to have imperative toxic side effects (Petrylak et al, 2004; Tannock et al, 2004). The search for more effective therapies has increased the interest in exploring the use of cellular immunotherapy as treatment against PC. 
Dendritic cells (DCs) are professional antigen-presenting cells because of their ability to efficiently activate $\mathrm{T}$ cells and to generate an adaptive immune response. Dendritic cells have been used in novel antitumour therapeutic strategies for several types of cancers (Hart, 1997; Banchereau et al, 2003). In PC, different approaches using prostate antigen-loaded DCs (peptides, proteins and mRNA) have been developed and tested in clinical trials (Tjoa et al, 1999; $\mathrm{Mu}$ et al, 2005; Fuessel et al, 2006). These strategies have proved to elicit immunological responses in patients, although only marginal clinical benefits have been achieved (Tjoa et al, 1999; Mu et al, 2005; Fuessel et al, 2006). A phase III clinical trial with Sipuleucel$\mathrm{T}$, an antigen-presenting cell-based immunotherapy against PC using prostatic acid phosphatase (PAP) as target tumourassociated antigen (TAA), has shown to improve overall survival of CRCP patients (Kantoff et al, 2010) and has been newly approved by the FDA for the treatment of advanced PC patients.

In our laboratory, we have performed two clinical trials using monocyte-derived DC vaccines for the treatment of advanced malignant melanoma (Escobar et al, 2005; López et al, 2009; Aguilera et al, 2011). Our data show that using these monocytederived DCs loaded with allogeneic melanoma lysates constitutes a safe procedure; able to increase the overall survival of stage IV melanoma patients and to inhibit tumour recurrence of stage III patients (López et al, 2009; Aguilera et al, 2011). In stage IV patients, delayed-type hypersensitivity (DTH) response against the melanoma lysate, which represents specific memory immune responses, was correlated with enhanced overall survival; where $\mathrm{DTH}^{+}$patients showed a median overall survival of 33 months $v s$ 11 months for $\mathrm{DTH}^{-}$patients (López et al, 2009; Aguilera et al, 2011). These results validate the use of allogeneic tumour lysates as an antigen source for inducing antitumour immunological memory, and DTH reaction as a useful immune-monitoring method in cancer immunotherapy. In addition, during those clinical trials, we demonstrated that TRIMEL, a heat-shocked melanoma lysate, has the ability to promote the maturation and activation of monocyte-derived DCs; and thus enabling them to activate antigen-specific $\mathrm{T}$ cells (Aguilera et al, 2011), which further suggests the lysate's role not only as antigenic source but also as a maturation stimulus. The lysate's effect seems to be mediated by the induction of danger signals, such as the release of HMBG1 and membrane mobilised calreticulin, which is differently induced in distinct cell lysates (Aguilera et al, 2011).

One major obstacle to a successful immunotherapy is breaking the self-tolerance to tumour antigens. Induction of antitumour T-cell responses by DC-based immunotherapies relies on the capability of vaccine formulations to strongly activate and to induce mature DCs (Joffre et al, 2009). To this end, clinically tested adjuvants, such as the hapten carrier protein keyhole limpet haemocyanin (KLH), have been used to enhance the efficacy of anticancer vaccines (Chiang et al, 2011; Del Campo et al, 2011). On the other hand, one of the significant drawbacks to the use of KLH as a TAAs carrier in antitumour vaccines is their poor solubility and propensity to aggregate and precipitate (Gathuru et al, 2005). This flaw has increased the interest in finding other haemocyanins with similar or better adjuvant/immunomodulatory properties, and enhanced structural stability. Recently, the haemocyanin derived from the gastropod Concholepas concholepas (Concholepas concholepas haemocyanin $(\mathrm{CCH})$ ) has been tested in vivo; showing its ability to activate innate immunity, inducing a Th1 cytokine profile and eliciting strong antitumour effects in a murine bladder cancer model, and therefore demonstrating its potential as an immunotherapeutic agent (Moltedo et al, 2006). In addition, $\mathrm{CCH}$ is a protein with a high solubility and stability (Idakieva et al, 2008).

At this point, we investigated whether the treatment of CRPC patients with DCs loaded with a PC cell lysate (PCCL), used, as antigen source and TRIMEL as DC activation factor, in combination with $\mathrm{CCH}$ as adjuvant, may constitute a safe therapy that is able to induce clinically relevant cellular responses. Consequently, the association between the level of prostate-specific antigen (PSA) in serum and specific immunological memory responses against PCCL, detected by DTH and $\mathrm{CD}^{+}$memory $\mathrm{T}$ cell (Tm) populations present in peripheral blood, was analysed.

\section{MATERIALS AND METHODS}

Patients. Twenty CRPC patients were recruited from January 2007 to December 2009 for a prospective phase I study. Inclusion criteria included histologically confirmed PC; progressive disease during combined ADT and androgen blockade (AB) according to PSA working group 2 criteria, an Eastern Cooperation Oncology Group performance status of 0 and 1 , an estimated life expectancy of $>6$ months, withdrawal of other oncological treatments (as radiotherapy or chemotherapy) at least for 4 weeks, haematocrit levels over $30 \%$, normal white blood cell count, normal liver function and serum creatinine under $1.5 \mathrm{mg} \mathrm{dl}^{-1}$. Exclusion criteria included steroidal therapy and second oncological disease. The present trial's primary end points were the immune response induction and the overall biosafety. Secondary end point was the vaccine effect on the PSA levels. The Bioethical Committee for Human Research of the University of Chile approved this study. Patients and healthy donors needed to understand and sign an informed consent statement. Non-orchiectomised patients were maintained under ADT with LHRH agonist or oestrogen throughout the study.

Haemocyanin source. Haemocyanin from Concholepas concholepas in PBS (0.1 M sodium phosphate, $0.15 \mathrm{M} \mathrm{NaCl}$; $\mathrm{pH} 7.2$ ) purified under sterile and pyrogen-free conditions and tested as LPS-free (Inmunocyanin) was provided by Biosonda Corporation (Santiago, Chile). All solutions were prepared using water for human irrigation (Baxter Healthcare Corp., Deerfield, IL, USA) and filtered through a $0.02 \mu \mathrm{m}$ membrane filter (Millipore, Billerica, MA, USA).

Cell lines and cell lysates. DU145, LNCaP and PC3 are PC cell lines (ATCC, Manassas, VA, USA). Prostate cancer cell lines were cultured in serum-free AIM-V medium (Invitrogen, Carlsbad, CA, USA), mixed in equal numbers, heat shocked at $42{ }^{\circ} \mathrm{C}$ for $1 \mathrm{~h}$, incubated for $2 \mathrm{~h}$ at $37^{\circ} \mathrm{C}$ and then lysed through repeatedly freeze-thaw cycles in liquid nitrogen. Next, the cell lysate was sonicated and irradiated $(80 \mathrm{~Gy})$. Lysate protein concentration was determined by Bradford's method using a Biophotometer (Eppendorf, Hamburg, Germany). TRIMEL is a standardised melanoma lysate generated at the Institute of Biomedical Sciences, Faculty of Medicine of the University of Chile (Aguilera et al, 2011). Microbiological tests were performed to rule out mycoplasma, retrovirus and bacterial presence in the cell lines and the lysates. The absence of trace amounts of LPS in the lysates was also confirmed.

Generation of tumour antigen-presenting cells (TAPCells). Adherent monocytes from peripheral blood mononuclear cells (PBMCs) of healthy donors $(n=3)$ were cultured for $22 \mathrm{~h}$ in serum-free AIM-V medium (Invitrogen), supplemented with recombinant human interleukin 4 (rhIL-4; $500 \mathrm{U} \mathrm{ml}^{-1}$; USBiological, Marblehead, MA, USA), and recombinant human granulocyte-macrophage colony-stimulating factor $\left(800 \mathrm{U} \mathrm{ml}^{-1}\right.$; Schering Plough, Kenilworth, NJ, USA). Then, monocytes were stimulated for $24 \mathrm{~h}$ with rhTNF- $\alpha\left(20 \mathrm{Uml}^{-1}\right.$; US-Biological), TRIMEL $\left(100 \mu \mathrm{g} \mathrm{ml}^{-1}\right)$ plus rhTNF- $\alpha\left(20 \mathrm{U} \mathrm{ml}^{-1}\right)$ (Trimel); PCCL $\left(100 \mu \mathrm{g} \mathrm{ml}^{-1}\right)$ plus rhTNF- $\alpha \quad\left(20 \mathrm{U} \mathrm{ml}^{-1}\right)$ (PCCL100); PCCL $\left(90 \mu \mathrm{g} \mathrm{ml}^{-1}\right)$ plus TRIMEL $\left(10 \mu \mathrm{g} \mathrm{ml}^{-1}\right)$ plus rhTNF- $\alpha\left(20 \mathrm{U} \mathrm{ml}^{-1}\right)$ (PCCL90 + Trimel10), PCCL $\left(80 \mu \mathrm{g} \mathrm{ml}^{-1}\right)$ plus TRIMEL $\left(20 \mu \mathrm{g} \mathrm{ml}^{-1}\right)$ 
plus rhTNF- $\alpha\left(20 \mathrm{U} \mathrm{ml}^{-1}\right)($ PCCL80 + Trimel20) or with medium only (activated monocytes (AMs)).

For vaccine production, PBMCs from PC patients $(n=20)$ were obtained by leukapheresis at the Blood Bank Service of the University of Chile Clinical Hospital as previously described (López et al, 2009). Adherent monocytes from PBMCs, cultured as described above for $22 \mathrm{~h}$, were then cultured for an additional $24 \mathrm{~h}$ with a mix of the PCCL $\left(80 \mu \mathrm{g} \mathrm{ml}^{-1}\right)$ and TRIMEL $\left(20 \mu \mathrm{g} \mathrm{ml}^{-1}\right)$ plus rhTNF- $\alpha\left(20 \mathrm{U} \mathrm{ml}^{-1}\right.$; US Biological). Afterwards, the cells were harvested and cryopreserved in liquid nitrogen until their use.

Phenotypic characterisation of TAPCells. Tumour antigen-presenting cells were phenotypically characterised by flow cytometry using the following monoclonal antibodies (mAbs): HLA-ABC, HLA-DRDQDP, CD80 and CD83 conjugated with fluorescein isothiocyanate (FITC; eBioscience, San Diego, CA, USA), CD86FITC (BD PharMingen, San Jose, CA, USA) and anti-CD11c conjugated with phycoerythrin (PE; eBioscience). Briefly, $1 \times 10^{6}$ cells were recovered from the culture plate and incubated with conjugated $\mathrm{mAbs}$ for $30 \mathrm{~min}$ at $4{ }^{\circ} \mathrm{C}$. Cells were fixed with paraformaldehyde (PFA) and analysed in a flow cytometer FACSort (Becton Dickinson, Franklin Lakes, NJ, USA). Data analysis was performed using the WinMDI 2.8 software (Purdue University, West Lafayette, IN, USA).

ELISPOT assay for IFN- $\gamma$ secretion. Peripheral blood mononuclear cells from healthy donors $(n=3)$ were cultured for $2 \mathrm{~h}$ in serum-free AIM-V medium (Invitrogen). Non-adherent peripheral blood lymphocytes (PBLs) were collected and cultured in RPMI medium supplemented with rhIL-2 $\left(20 \mathrm{U} \mathrm{ml}^{-1}\right)$ along with autologous prostate-loaded TAPCells (Pro80 + Trimel20) in a $10: 1$ ratio. On day 4 of culture, rhIL-2 $\left(20 \mathrm{U} \mathrm{ml}^{-1}\right)$ was added to the medium. At day 8, autologous TAPCells were again added to the culture. Finally, at day 14, PBL were rescued from the culture. Pre-stimulated and non-stimulated PBL were co-cultured overnight with $2 \times 10^{5}$ autologous TAPCells at different effectors/target ratios (E:T 20:1, 10:1 vs 5:1). IFN- $\gamma$ secretion was tested by ELISPOT assay, as described (Escobar et al, 2005).

Clinical protocol and DTH assay. At days 1, 10, 30 and 60, patients were immunised subcutaneously with a mix of $2 \times 10^{7}$ autologous TAPCells in $400 \mu \mathrm{l}$ of frozen medium ( $90 \%$ autologous $\mathrm{AB}$ serum $10 \% \mathrm{DMSO}$ ) plus $150 \mu \mathrm{g} \mathrm{CCH}$ in $200 \mu \mathrm{l}$ of saline solution as an adjuvant. Before each immunisation, $50 \mathrm{ml}$ of peripheral blood was collected in heparinised tubes, separated by Ficoll-Hypaque (Axis-Shield, Oslo, Norway) gradient to obtain PBMCs and then cryopreserved in liquid nitrogen.

One month after the end of the therapy, patients were evaluated for in vivo DTH reaction against PCCL and controls. Skin tests were performed by intradermal injections of $100 \mu \mathrm{l}$ of PCCL $\left(4 \mu \mathrm{g} \mu \mathrm{l}^{-1}\right)$, CCH $100 \mu \mathrm{l}\left(1 \mu \mathrm{g} \mu \mathrm{l}^{-1}\right)$, KLH $100 \mu \mathrm{l}\left(1 \mu \mathrm{g} \mu \mathrm{l}^{-1}\right)$ or $100 \mu \mathrm{l}$ of saline solution (as negative control) at three different sites. A positive DTH reaction was defined as skin induration and erythema equal or larger than $5 \mathrm{~mm}$ at $48 \mathrm{~h}$ after injection.

Toxicity and quality of life. Toxicity was evaluated during every immunisation and DTH test, using the NCI Common Terminology Criteria for Adverse Events Cancer Therapy Evaluation Program (CTCAE, Bethesda, MD, USA) v.3.0. In addition, patients had a 24-h emergency phone number to report adverse events.

Quality of life was evaluated at immunisation 1, 3 and 4, and also at DTH test. We used the European Organization for Research and Treatment of Cancer Quality of Life Core Questionnaire (EORTC QLQ-C30), in Spanish language and validated in Chile. Scores for every scale were calculated according to EORTC instructions.

Clinical response. Serum PSA levels were measured monthly from the onset of the therapy. The PSA baseline is the level showed the week before treatment. The PSA Nadir is the absolute lowest level that the PSA drops after treatment. Prostate-specific antigen doubling-time (PSADT) was calculated using all available serum PSA measuring over the last 12 months before the treatment. We utilised the Memorial Sloan-Kettering Cancer Centre PSADT calculator, based on the formula PSADT $=\log 2 \times \mathrm{dT} /(\log \mathrm{B}-$ $\log A$ ), available on the website (http://nomograms.mskcc.org/ Prostate/PsaDoublingTime.aspx).

In addition, we evaluated metastatic disease with bone scan and abdomino-pelvic CT scan 1 week before and 1 week after the treatment.

Determination of $\mathrm{Tm}$ populations. T-cell populations from treated patients PBMCs were collected before the first immunisation and at the DTH test time. Peripheral blood mononuclear cells were stained using the following mAbs: CD8-FITC, CD45ROPe-Cy5 and CD62L-PE; CCRP7-PE or CD28-PE (e-Bioscience). Stained samples were acquired on a FACScan (Becton Dickinson) and analysed using the WinMDI 2.8 software.

Determination of intracellular cytokines (IFN- $\gamma$, perforin and granzyme B). Peripheral blood mononuclear cells obtained before the first immunisation and at the DTH test time were cultured overnight on RPMI 10\% FBS with autologous DCs loaded with PCCL. Next, the cells were incubated with Brefeldin A $\left(10 \mu \mathrm{g} \mathrm{ml}^{-1}\right.$; e-Bioscience) for $4 \mathrm{~h}$, collected and stained with anti-CD8-FITC and anti-CD45RO-PECy5 mAbs. After that, cells were fixed with PFA $1 \%$, permeabilised with saponin $0.1 \%$ and incubated with anti-IFN- $\gamma$-PE, anti-granzyme B-PE (e-Bioscience) or antiperforin-PE (Becton Dickinson) mAbs. Stained samples were acquired on a FACScan (BD) and analysed using the WinMDI 2.8 software.

Statistical analysis. The normal distribution of the data was evaluated using Skewness/Kurtosis, Shapiro-Wilk and ShapiroFrancia tests. For the analyses of paired samples, $t$-test and Wilcoxon rank-sum test were applied. For non-paired samples, Mann-Whitney tests were used. For grouped samples, ANOVA tests were utilised. Statistical significance was considered at a $P$-value $\leqslant 0.05$. Results are shown as means $(95 \%$ confidence interval, CI). Statistical analyses were performed using Graph Pad Prism 4 software (GraphPad Software, Inc. La Jolla, CA, USA).

\section{RESULTS}

Combination of PCCL with TRIMEL induces APCs maturation and activation. We have previously demonstrated that TRIMEL, a conditioned melanoma lysate, has the ability to induce a fast, full mature and activated DC phenotype on APCs that we named TAPCells (Aguilera et al, 2011). Similarly, we have shown that other tumour cell lysates (derived from renal, breast and colon cancer) increased the expression of maturation markers on DCs (Aguilera et al, 2011). Considering this ability of conditioned tumour lysates, we decided to generate fast-differentiating TAPCells using PCCL as antigenic source and as maturation stimulus. We observed that heat-shocked PCCL (PCCL100) slightly increased the expression of MHC I and II molecules and coestimulatory molecules CD80 and CD86, although at lower levels compared with TRIMEL alone (Figure 1A). For that reason, we combined PCCL with TRIMEL as maturation stimulus at different proportions. We observed that the combination of PCCL $\left(80 \mu \mathrm{g} \mathrm{ml}^{-1}\right)$ with TRIMEL $\left(20 \mu \mathrm{g} \mathrm{ml}^{-1}\right)$ (PCCL80 + TRIMEL20) increased the expression of MHC class I and II molecules and maturation markers CD83, CD80 and CD86 similarly to TRIMEL alone $\left(100 \mu \mathrm{g} \mathrm{ml}^{-1}\right.$; Figure $\left.1 \mathrm{~A}\right)$.

Next, we evaluated the ability of PCCL-loaded TAPCells to activate $\mathrm{T}$ lymphocytes. We stimulated PBLs from healthy donors with 

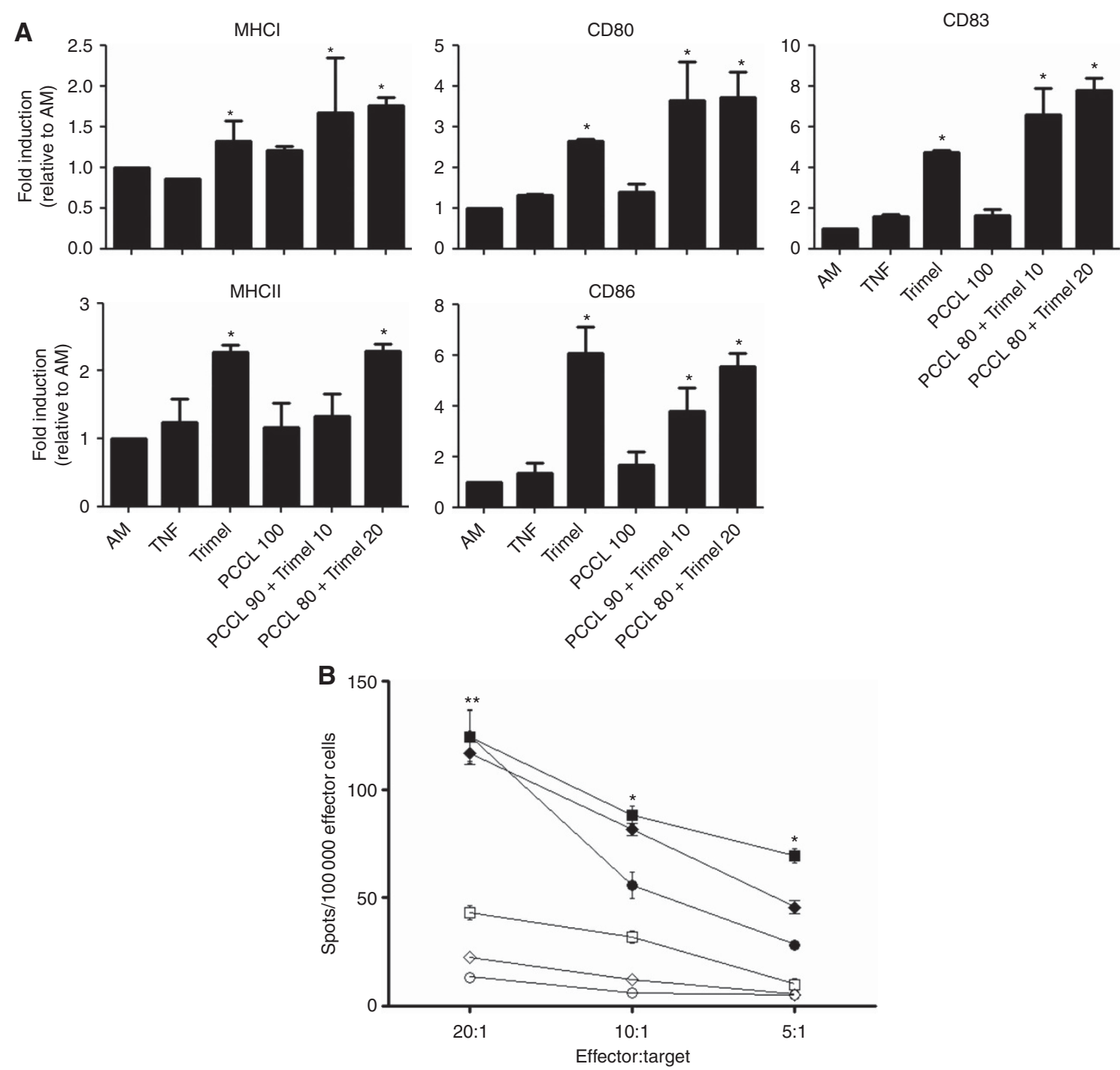

Figure 1. PCCL, together with TRIMEL and TNF- $\alpha$, induces a fast differentiation of active APCs (TAPCells) from peripheral blood monocytes. (A) PBMCs from healthy donors $(n=3)$ were incubated in supplemented AIM-V medium. Next, adherent cells were stimulated for $24 \mathrm{~h}$ with TNF- $\alpha$

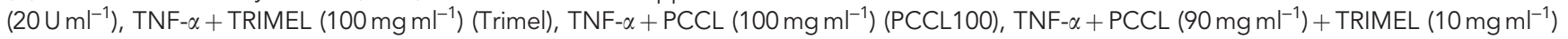
(PCCL90 + Trimel10) or TNF- $\alpha+$ PCCL $\left(80 \mathrm{mg} \mathrm{ml}^{-1}\right)+$ TRIMEL $\left(20 \mathrm{mg} \mathrm{ml}^{-1}\right)$ (PCCL80 + Trimel20). AM, non-stimulated monocytes. Expression of $\mathrm{MHC}$ molecules and maturation markers were determined using flow cytometry over $\mathrm{CD} 11 \mathrm{c}^{+}$population. Graphics represent mean fold induction relative to $A M\left({ }^{*} P<0.05\right.$, t-test). (B) Stimulated (filled figures) and non-stimulated (clear figures) PBLs from healthy donors $(n=3)$ were cultured with PCCL-loaded APCs (PCCL80 + Trimel20) for $16 \mathrm{~h}$. IFN- $\gamma$ secretion was measured by ELISPOT assay. Experiments were performed in triplicate $\left({ }^{\star} P<0.05,{ }^{\star \star} P<0.01\right.$, ANOVA). Every symbol (circle, square and rhombus) represents a different donor.

PCCL-loaded autologous TAPCells for 2 weeks. After two rounds of stimulation, APC-stimulated and non-stimulated PBLs were evaluated for IFN- $\gamma$ secretion in an ELISPOT assay. PC cell lysate-loaded autologous TAPCells were used as target cells. We observed that stimulated PBLs increased two- to eight-fold the IFN- $\gamma$ secretion compared with non-stimulated PBLs (Figure 1B). Altogether, these results showed that the combination of PCCL with TRIMEL induces the differentiation of mature, functionally activated APCs (TAPCells); and therefore this lysate combination was clinically tested.

Patient demographic description and treatment adherence. Twenty CRPC patients were recruited for this study. Patient's demographic characteristics are described in Table 1. Eleven patients received $\mathrm{ADT}$ as primary treatment and nine were initially treated as organ-confined PC (eight patients underwent retropubic radical prostatectomy and one patient received external beam radiotherapy). During ADT, all patients were submitted to $\mathrm{AB}$ using flutamide or bicalutamide as anti-androgens.
In addition, 15 patients were treated with oestrogens as second-line hormonal therapy, and one patient received a third-line hormonal treatment with ketoconazol plus steroids. Only one recruited patient had been previously treated with docetaxelbased chemotherapy.

In all, 14 out of 20 patients presented metastatic disease, all of them compromising pelvic nodes and bone tissues, but none of these patients showed visceral metastases. For CRPC diagnosis, seven patients showed progressive metastatic disease under ADT plus $\mathrm{AB}$, but all patients showed biochemical progression.

In total, 14 out of 20 recruited patients completed the treatment protocol. Two patients did not perform the DTH test because they presented a fast rise of serum PSA and decided to abandon the study. Two patients did not complete the treatment because of the lack of adherence to the protocol. One patient needed to use oral steroids after the second immunisation and he was also excluded from the study. Another patient presented a lower extremity 


\begin{tabular}{|c|c|c|}
\hline Age (years)-mean (range) & 69 & $(54-84)$ \\
\hline \multicolumn{3}{|l|}{ Initial treatment, $\mathbf{n}(\%)$} \\
\hline $\begin{array}{l}\text { Curative intention } \\
\text { Primary ADT }\end{array}$ & $\begin{array}{c}9 \\
11\end{array}$ & $\begin{array}{l}(45) \\
(55)\end{array}$ \\
\hline \multicolumn{3}{|l|}{ ADT method, $\boldsymbol{n}(\%)$} \\
\hline $\begin{array}{l}\text { Bilateral orchiectomy } \\
\text { LHRH agonists }\end{array}$ & $\begin{array}{c}9 \\
11\end{array}$ & $\begin{array}{l}(45) \\
(55)\end{array}$ \\
\hline \multicolumn{3}{|l|}{ Second-line treatment, $n(\%)$} \\
\hline $\begin{array}{l}\text { Oestrogens } \\
\text { Ketoconazol plus prednisone } \\
\text { Chemotherapy }\end{array}$ & $\begin{array}{c}15 \\
1 \\
1\end{array}$ & $\begin{array}{l}(75) \\
(5) \\
(5)\end{array}$ \\
\hline Duration of ADT, months (range) & 24,5 & $(6-81)$ \\
\hline \multicolumn{3}{|l|}{ Metastases, $\boldsymbol{n}(\%)$} \\
\hline $\begin{array}{l}\text { Bone } \\
\text { Lymph node } \\
\text { Visceral } \\
\text { None }\end{array}$ & $\begin{array}{c}14 \\
14 \\
0 \\
6\end{array}$ & $\begin{array}{l}(70) \\
(70) \\
(0) \\
(30)\end{array}$ \\
\hline \multicolumn{3}{|l|}{ Progression, $n$ (\%) } \\
\hline $\begin{array}{l}\text { Biochemical } \\
\text { Metastases }\end{array}$ & $\begin{array}{c}13 \\
7\end{array}$ & $\begin{array}{l}(65) \\
(35)\end{array}$ \\
\hline Patients that completed treatment protocol, $n(\%)$ & 14 & (70) \\
\hline
\end{tabular}

paraparesis, 10 days after the second immunisation; this patient had a history of lumbar spine metastases and an MRI confirmed spinal cord compression, secondary to lumbar metastases. The patient started oral steroids and was excluded from the treatment protocol.

Treatment toxicity and its effect on patient quality of life. Observed adverse events are described in Table 2. A total of 10 adverse events were registered, being 8 cases of pain and erythema in the inoculation site after the third or fourth immunisation. All skin inflammatory events were self-limited, with a maximum duration of $48 \mathrm{~h}$. None of the patients required any treatment for those adverse events. The last adverse event was self-limited asymptomatic hypertensive urgency, presented $12 \mathrm{~h}$ after the third immunisation and lasting for $6 \mathrm{~h}$. That patient had the clinical antecedent of arterial hypertension. No grade 4 or greater adverse events were observed in this study.

In spite of this, the EORTC QLQ-C30 symptom section showed an increase in nausea and vomiting symptoms during the treatment protocol (Supplementary Figure 1A). The patients did not mention these emetic symptoms. The score of nausea and vomiting item was significantly greater after the third and fourth immunisation. In order to explain the increase in the incidence of nausea and vomiting, we analysed the correlation of emetic events with the use of opioids as part of palliative care. The increase in emetic score was observed exclusively in patients who used opioids for bone pain management (Supplementary Figure 1B). We did not observe any change in the other eight symptoms evaluated by the EORTC QLQ-C30 (Supplementary Figure 1C).

In addition, we evaluated the impact of the treatment over the quality of life, using the EORTC QLQ-C30 scale from the start of treatment until the DTH test. Both the quality of life and functional subscales scores remained over 80 points during the

Table 2. Adverse events
\begin{tabular}{|l|c|c|}
\hline Event & All grades, N & Grades 3-5 \\
\hline Any event & 10 & 1 \\
\hline Pain and erythema in punction site & 8 & 0 \\
\hline Lower extremities paraparesis & 1 & 1 \\
\hline Hypertensive crisis & 1 & 0 \\
\hline
\end{tabular}

treatment. We did not observe any change in all six functional subscales evaluated by QLQ-C30 during the treatment (Supplementary Figure 2), and hence indicating that the treatment did not affect the quality of life parameters.

TAPCells immunotherapy induces PCCL-specific T-cell cytokine release in vitro and DTH reaction in vivo. To determinate whether the treatment had the ability to induce specific cellular immune responses, we performed IFN- $\gamma$ secretion ELISPOT assays before the onset of the therapy and after the fourth immunisation, using PBL as effector cells and tumour cell lysate-loaded autologous DCs as stimulators. We observed that 7 out of 14 patients showed an effector cell number dependence increase in IFN $-\gamma$ secretion after the therapy as showed for 2 representative patients PT129 and PT134 (Figure 2A). The rest of the patients showed no difference between before and after vaccination as exemplified for PT78 and PT92 (Figure 2A). None of the patients showed decreased IFN $-\gamma$ secretion at the end of the therapy.

Moreover, we evaluated the presence of in vivo specific cellular immune response against the PCCL and the adjuvant $\mathrm{CCH}$ in vivo using the DTH test as a clinically relevant parameter, since in our previous studies in malignant melanoma, the DTH test and not the in vitro immune assays, were correlated with overall survival. In this report, 9 out of 14 patients showed a positive DTH reaction against the PCCL, whereas all 14 patients developed a positive $\mathrm{DTH}$ test against the $\mathrm{CCH}$ adjuvant (Figure 2B). In some patients, DTH reactions against KLH were also detected indicating a crossreaction with $\mathrm{CCH}$ after immunisation (Figure $2 \mathrm{~B}$ ). No patients showed a DTH reaction when saline solution was injected as a control. These results suggest that TAPCell-based immunotherapy is able to induce specific immune responses in a fraction of the patients, and the $100 \%$ reactivity against the adjuvant indicates that non-responder patients do not fail to respond because of a global immunosuppressive condition, and rather suggests a patientdependent tolerance status.

PCCL/TRIMEL-loaded TAPCells vaccine induces an increase of functional $\mathrm{CD8}^{+}$IFN- $\gamma^{+}$memory T-cell population. To further gain insight into the $\mathrm{DC}$ vaccine induction of specific immune responses detected by ELISPOT and DTH test, we decided to evaluate the induction of a $\mathrm{CD} 8{ }^{+}$memory $\mathrm{T}$-cell population $(\mathrm{Tm})$, which was previously correlated with the antitumour efficacy (Klebanoff et al, 2006). We observed that the total $\mathrm{CD}^{+} \mathrm{CD}^{+} 5 \mathrm{RO}^{+}$ T-cell population remained stable during the whole treatment period (from $10.1 \%$ to $13.56 \%$ of $\mathrm{CD}^{+} \mathrm{T}$ cells, $P=0.239$; Figure $3 \mathrm{~A}$ ). Similarly, the total $\mathrm{CD}^{+}$T-cell population remained also stable until the end of the therapy (data not shown). Interestingly, IFN- $\gamma^{+}$ Tm cells, a population related to the DTH reaction and antitumour responses, increased after treatment from a mean of $9.6 \%$ to $19.8 \%$ of $\mathrm{CD}^{+} \mathrm{CD}^{+} 5 \mathrm{RO}^{+} \mathrm{T}$ cells in all-treated patients (Figure $3 \mathrm{~B}$ ). In contrast, we observed no changes in neither the expression of the cytotoxic molecules granzyme B or the perforin in Tm cells, nor changes in the central or peripheral Tm subsets (Supplementary Figure 3). No statistical differences were observed in the $\mathrm{CD} 4^{+}$ population (data not shown).

Immunotherapy reduces serum PSA levels and improves PSADT in immune-responder patients. We evaluated the 
A

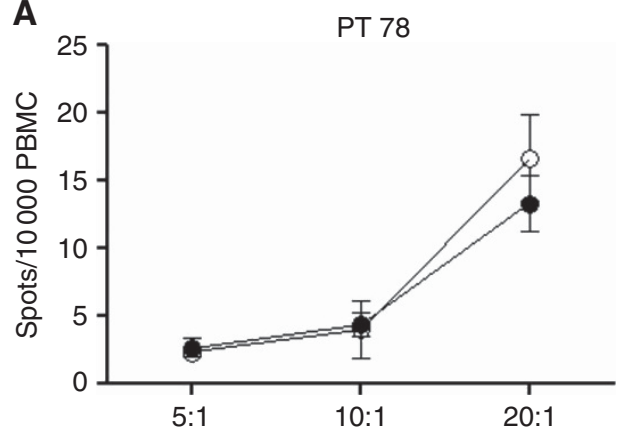

PT 134

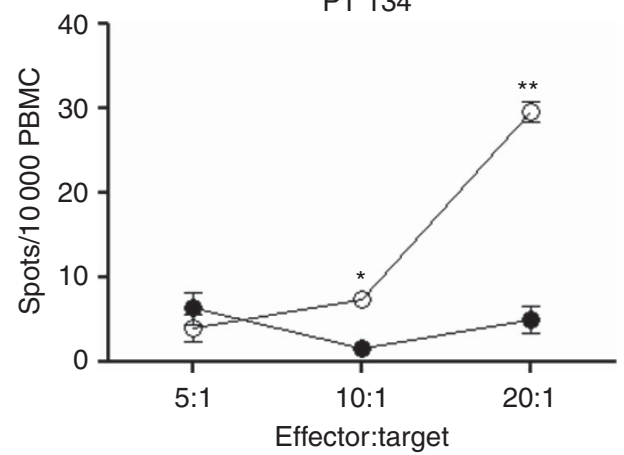

B

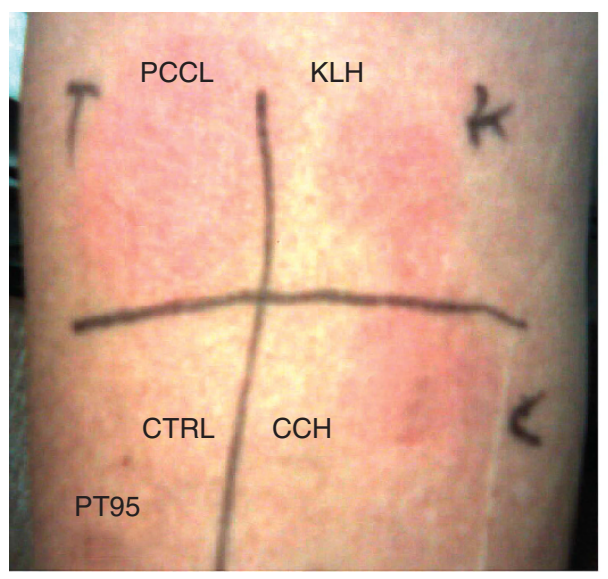

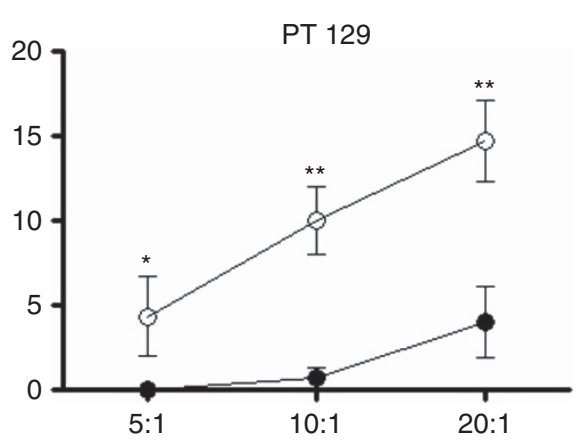

PT 92
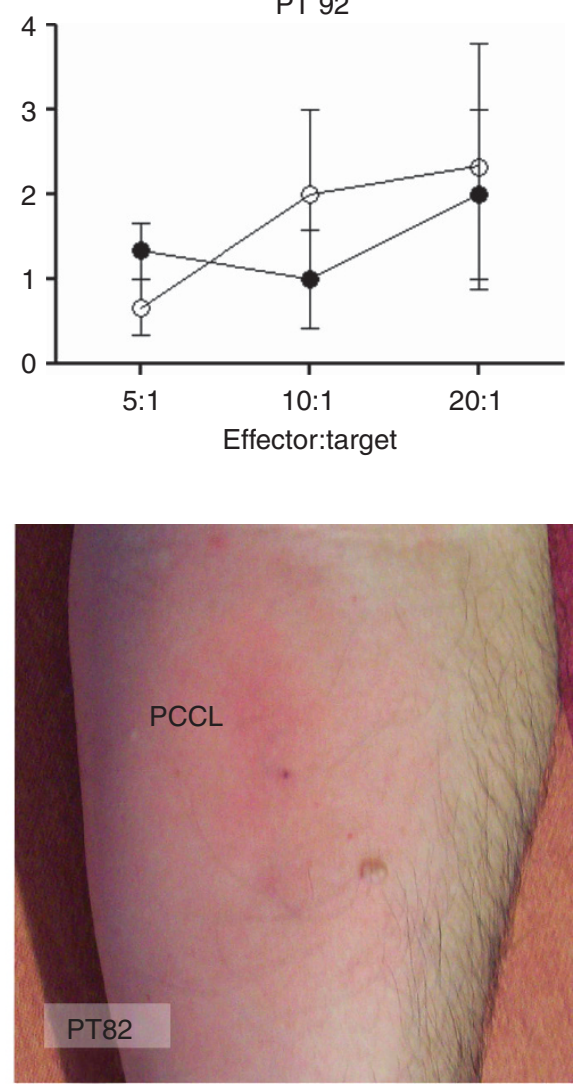

Figure 2. PCCL-loaded TAPCells immunotherapy is able to induce specific immune response in CRPC patients. (A) PBMCs obtained before (filled circles) or at the end of treatment (clear circles) were co-cultured with DCs loaded with PCCL and in vitro immune response was evaluated by IFN- $\gamma$ ELISPOT assay. Graphics are representative of four patients. (B) DTH test against tumour lysate. Thirty days after the fourth immunisation, patients were inoculated subcutaneously with $\mathrm{PCCL}, \mathrm{CCH}, \mathrm{KLH}$ or saline solution (Ctrl). Skin inflammatory reaction was evaluated $48 \mathrm{~h}$ later. Pictures are representative of two patients. Experiments were performed in triplicate $\left({ }^{\star} P<0.05, \star \star P<0.01\right.$, ANOVA).

capacity of TAPCell-based immunotherapy to generate clinical responses, measured as serum PSA levels and changes in bone scan 1 month after the end of treatment protocol (DTH time). We observed decreased levels of PSA serum in 10 patients, including a $30 \%$ greater decrease than the PSA baseline in 4 patients and $50 \%$ greater in another 2 patients (Figure 4). All Nadir PSA levels were observed between third immunisation and DTH test evaluation. It is worthy to note that 9 out of 10 patients who presented decreased serum PSA levels were DTH-positive. There was no correlation between biochemical responses and in vitro $\mathrm{T}$-cell responses measured by ELISPOT.

Correspondingly, we evaluated whether the treatment could improve the calculated PSADT, which was previously described as a prognostic factor in CRPC (Semeniuk et al, 2006). We observed that calculated PSADT in treated patients increased from a median of 5.1 months before treatment to 6.4 months, 3 months after the end of the therapy, although that difference was not statistically significant
(Figure 5A). Remarkably, we observed that the PSADT increased in DTH-positive patients from a median of 6.5 before treatment up to 8.2 months, 1 month after treatment (DTH time), and up to 12.1 months, 3 months after the end of the therapy (Figure 5B; $P<0.05$, ANOVA.). In contrast, non-responder patients showed a calculated PSADT of 3 months, without any change during the treatment. Despite the effect of the PSADT, we observed no changes in metastatic lesions at the end of the treatment protocol.

\section{DISCUSSION}

The use of DC-based vaccines as an immunotherapeutic strategy against cancer pursues to induce and enhance T-cell-mediated antitumour immune responses. This strategy resembles physiologic mechanisms, where DCs loaded with tumour antigens are able to 
A

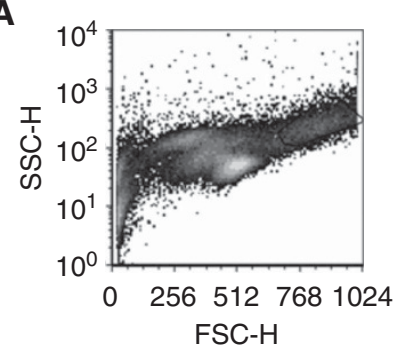

B

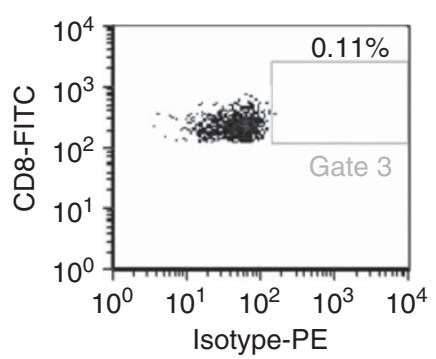

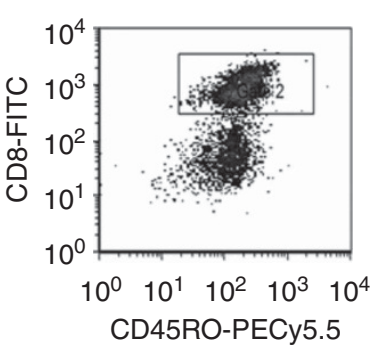
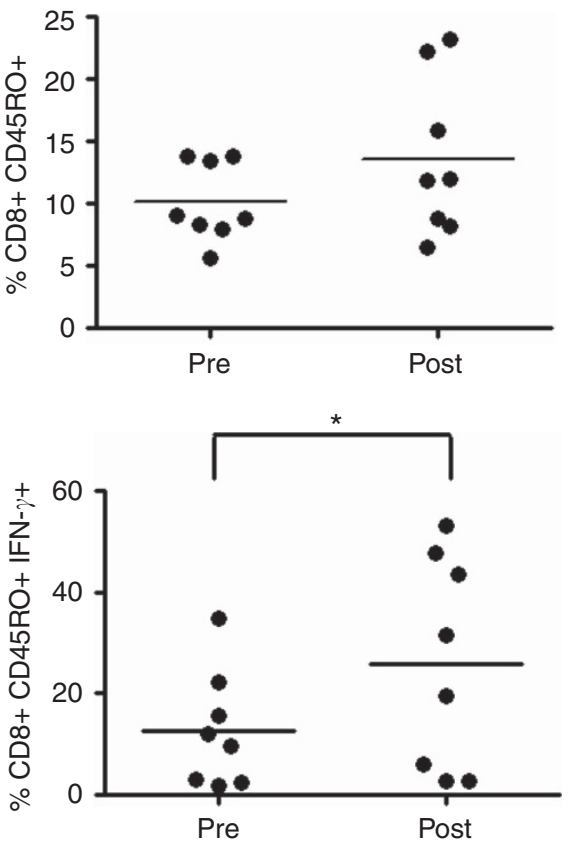

Figure 3. PCCL-loaded TAPCells immunotherapy increases IFN- $\gamma$-producing memory T-cell population. PBMCs obtained before the first immunisation (Pre) and at DTH test time (Post) were co-cultured overnight with autologous PCCL-loaded TAPCells, and analysed by FACS. (A) Proportion of $\mathrm{CD} 45 \mathrm{RO}{ }^{+} \mathrm{T}$ cells over $\mathrm{CD} 8^{+}$population. (B) Proportion of IFN- $\gamma^{+} \mathrm{T}$ cells over $\mathrm{CD} 8^{+} \mathrm{CD} 45 \mathrm{RO}{ }^{+}$population $(P<0.05 t$-test).

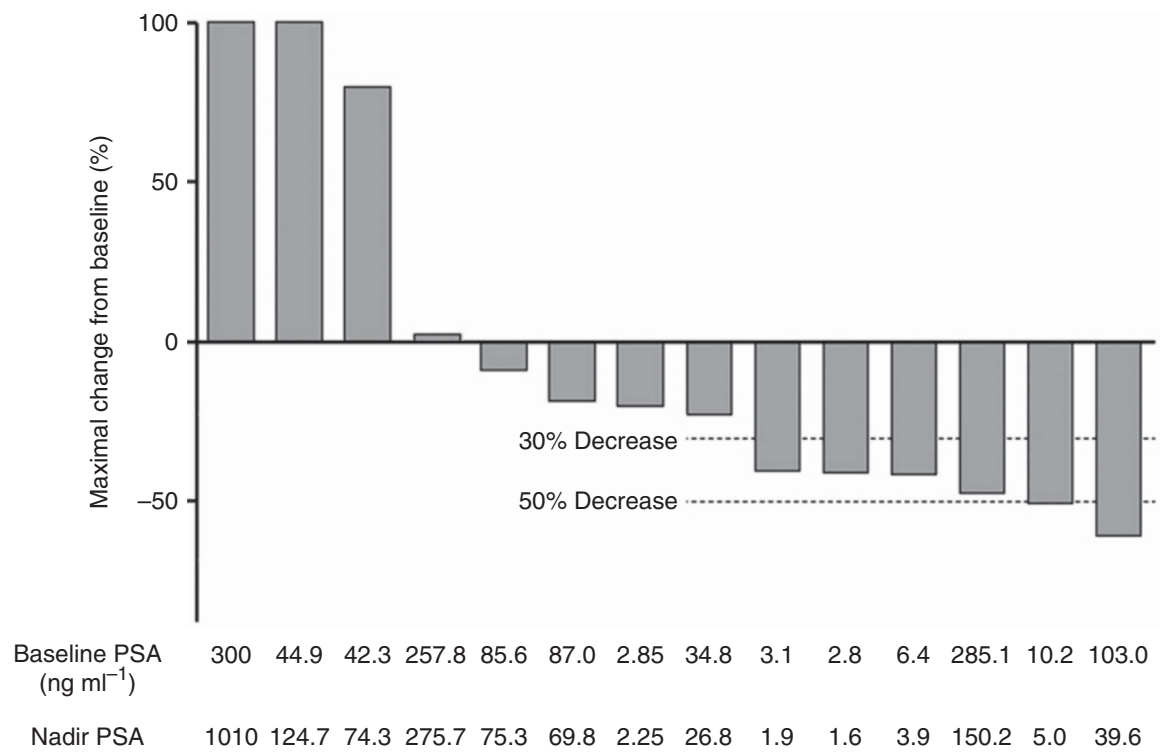

Figure 4. PCCL-loaded TAPCells immunotherapy reduces serum PSA levels. Serum PSA was evaluated monthly from the treatment onset until DTH test. Graphic shows change of PSA from baseline. The PSA Nadir is the absolute lowest level that the PSA drops after treatment. Every bar corresponds to a different patient.

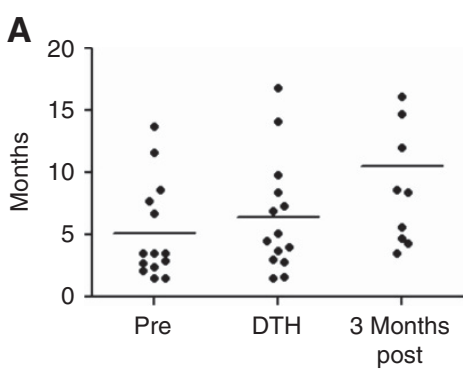

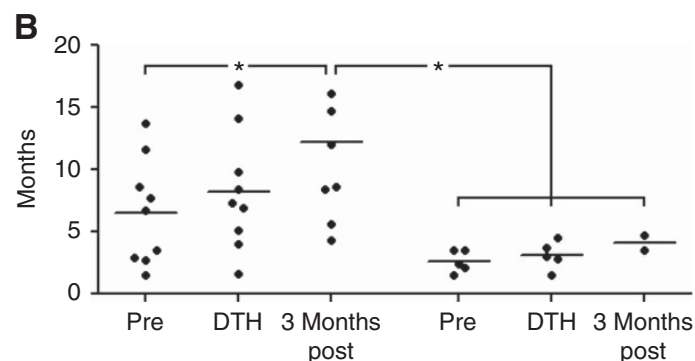

DTH-positive patients

DTH-negative patients

Figure 5. Treatment improves PSADT in immunologic-responder patients. PSADT was calculated using all available previous PSA. (A) Mean of PSADT in all-treated group. (B) Mean of PSADT by immunologic response, determined by DTH test $(P<0.05, A N O V A)$. 
prime tumour antigen-specific $\mathrm{T}$ cells. Effective T-cell priming requires adequate DC maturation and activation. Resting DCs or DCs exposed to an anti-inflammatory environment displayed an immature phenotype, and generated T-cell tolerance (Joffre et al, 2009) that could explain reports showing that DC-based immunotherapies can stimulate the proliferation of regulatory T cells (López et al, 2006). Our protocol to generate TAPCells has demonstrated to produce mature DCs with the capacity to induce specific T-cell activation and clinical responses in malignant melanoma patients (López et al, 2009; Aguilera et al, 2011). The cancer cell lysate used in these studies as the antigenic source contains 'danger' signals, such as HMGB1 and Calreticulin, which are capable to interact TLR4 and rage on the APC-promoting DC immunogenicity (Tittarelli et al, 2012). Other tumour lysates also contain danger signals that can induce DC maturation and activation, but our melanoma cell lysate (TRIMEL) displayed a comparatively stronger activity (Aguilera et al, 2011). For this reason, we used a low proportion of TRIMEL together with PCCL in this study. The presence of TRIMEL seems to contribute to the increase in the activation and maturation of DCs (Figure 1), and further adding to a better immune response of vaccinated patients.

DTH test is one of the main methods used for monitoring immune responses in clinical trials (deVries et al, 2005). A positive $\mathrm{DTH}$ response is mediated by the activation of antigen-specific $\mathrm{CD}^{+}$memory $\mathrm{T}$ cells against an antigen, which induces the production of Th1 cytokines like IFN- $\gamma$ and the recruitment of $\mathrm{CD}^{+} \mathrm{T}$ cells and other inflammatory cells (Kobayashi et al, 2001). Although some reports have suggested that the DTH test is not an appropriate method for immune monitoring because of the difficulty to standardise it and the generation of a DTH response against non-antigenic compounds; other studies have showed that DTH test is a reproducible and cost-effective method for predicting clinical benefits (deVries et al, 2005). Delayed-type hypersensitivity reaction has showed to be an in vivo good prognosis predictor in some cancer immunotherapy trials (deVries et al, 2005; López et al, 2009). In our previous works, $60 \%$ of treated melanoma patients showed a positive DTH reaction against melanoma lysate, and such DTH response correlated with improved median survival (López et al, 2009; Aguilera et al, 2011). In this report, we observed a similar proportion of DTH-positive responder patients against the PCCL (immune-responder). We can assume that the induction of DTH against the PCCL reflects the generation and activation of clinically relevant $\mathrm{CD} 4{ }^{+} / \mathrm{CD} 8{ }^{+}$memory $\mathrm{T}$-cell responses. Accordingly, $\mathrm{CD} 4{ }^{+}$helper $\mathrm{T}$ cells are crucial for an adequate generation and activation of memory $\mathrm{CD} 8{ }^{+} \mathrm{T}$ cells. A positive DTH response is an indicator of the induction of these cells (Shedlock and Shen, 2003; Aguilera et al, 2011). Furthermore, we showed that IFN- $\gamma$ producing Tm populations are increased after the treatment in our cohort of patients. The increasing of memory $\mathrm{T}$ cells after treatment is directly related to the DTH response; demonstrating a participation of this memory $\mathrm{T}$-cell population in the immune reaction of responder patients. In addition, IFN- $\gamma$-producing Tm has been associated with antitumour immune responses, explaining in part the biochemical response observed in some of our patients (Pagès et al, 2009). In fact, an increase in the IFN- $\gamma$ producing and IL-17-producing T-cell populations has recently been associated with the improved overall survival in DC-treated melanoma patients (Durán-Aniotz et al, 2013). However, we observed no increase in the expression of cytotoxic molecules granzyme $\mathrm{B}$ and perforin in vitro; suggesting that our vaccine may influence the relative number of cells, but not the potency of tumour-reactive $\mathrm{T}$ cells. Similar to other reports, in vitro T-cell cytokine release responses measured by ELISPOT showed no correlation with clinical response (Pandha et al, 2004).

Accordingly to accumulated evidences, the properties of adjuvants are fundamental to generating an inflammatory environment for the correct induction of an immune response.
In melanoma studies, we showed that KLH constituted a potent inductor of immunogenicity (Escobar et al, 2005). Here we used for the first time the CCH (De Ioannes et al, 2004) as an adjuvant in a DC-based cancer vaccine. Previously, using a murine model of bladder cancer, $\mathrm{CCH}$ demonstrated to induce a Th1 cytokine profile and elicit strong antitumour effects (Moltedo et al, 2006), as well as in a mouse melanoma model (Arancibia et al, 2012). In our present clinical study, $\mathrm{CCH}$ was able to induce an immune memory response measured by DTH test, and we observed no toxic or allergic adverse reactions related to the subcutaneous administration of this compound. Therefore, Concholepas haemocyanin may be considered as an alternative to KLH for providing safe and effective adjuvanticity for cancer vaccines.

Similar to other studies, TAPCell-based immunotherapy shows to be a safe and non-toxic treatment with few adverse events related to the therapy. Almost all adverse events reported here were inflammatory skin reactions in the inoculation site that correlated with a positive DTH test at the end of the study. Although the EORTC QLQ-C30 questionnaire detected an increase in emetic symptoms during the therapy, they correlated with the use of narcotic analgesics. It is well known that nausea and vomiting are frequent symptoms in cancer patients (Shoemaker et al, 2011) and secondary effects to opioid treatments (Watcha and White, 1992). Other reports including DC-based immunotherapy have not described emetic symptoms as an adverse event, although IMPACT study described a $28 \%$ of patients presenting nausea (Kantoff et al, 2010). In the same way, global health status and functional scales of treated patients, although not improved, remained stable during the treatment. We also observed that the functional scores were similar to those described for stage III and stage IV PC patients (Sullivan et al, 2007).

Although the main goal of the present phase I trial was the induction of specific immune response, we also observed a biochemical response in some patients, with 6 out of 14 patients showing a significant decrease in PSA serum (30\% or greater from baseline); contrasting to previous studies using DCs loaded with different antigen sources (as peptides, proteins or mRNA) that reported reduced levels of PSA serum in limited cases (Tjoa et al, 1999; Mu et al, 2005; Fuessel et al, 2006). However, because our patient cohort was heterogeneous, including both metastatic and non-metastatic patients, we cannot discard that the different stages and pre-treatment PSA levels can determine the observed biochemical responses. In a recently finalised phase III trial, Sipuleucel-T, a DC-based immunotherapy loaded with a fusion protein between PAP and GM-CSF, showed an improved overall survival in CRPC patients, without a decrease in PSA levels during the treatment (Kantoff et al, 2010).

Although survival was not evaluated in this study, we observed an improvement in PSADT in immune-responder patients. Prostate-specific antigen doubling-time is a recognised prognostic factor, and correlates with the outcome and overall survival of CRPC (Semeniuk et al, 2006). We want to appoint that only one metastatic patient in our group received docetaxel during the study. Although docetaxel has been suggested as a first-line therapy in metastatic (CRPC patients; Mottet et al, 2011), this chemotherapy unfortunately is not supported yet by public health in our country. For that reason, most of CRPC patients in Chile are actively monitored and do not receive chemotherapy. Importantly, in the DTH-positive patients, the PSADT continue to get better 3 months after treatment (Figure 5B). A delayed treatment effect has been previously noted for other immunotherapies, like the antiCTLA-4 (ipilimumab; Hodi et al, 2010) or a combination of anti CTLA-4 and PD1 receptor antibody (Nivolumab) in melanoma (Wolchok et al, 2013). It would also be important to note that the increase in doubling time did not include two patients. These two patients progressed quickly and could not be evaluated and may affect the observed post-treatment PSADT. As the low number of 
analysed patients strongly limits the conclusions raised by this study, it becomes necessary to design and develop a phase II trial to establish the real clinical impact of our treatment on PSADT and overall survival. At this respect, a more accurate selection of patients, excluding non-responding advanced bone metastatic patients, need to be performed to increase the effect of our therapy in a future phase II clinical trial.

Immunotherapy may constitute an interesting alternative for some patients, particularly if used in combination with other systemic therapies. In fact, emerging evidence indicates that the antitumour activities of chemotherapy rely on several off-target effects, particularly directed to the host immune system, that cooperate for successful tumour eradication (Bracci et al, 2013; $\mathrm{Ma}$ et al, 2013). Among the indirect ways of immune cell stimulation, some cytotoxic drugs have been shown to enhance an immunogenic type of cell death in tumour cells, resulting in the emission of specific signals that trigger phagocytosis of cell debris and promote the maturation of DCs, ultimately resulting in the induction of potent antitumour responses. At this respect, some experiences, combining immunotherapy with chemotherapy have been explored in melanoma and retinoblastoma (Liu et al, 2013; Weber et al, 2013).

In conclusion, our study suggests that TAPCell-based immunotherapy against PC is a safe approach that is capable to induce memory T-cell responses as determined in vivo (DTH) and in vitro (cytokine release) that could be associated with clinical responses including, decreased serum PSA levels and enhanced PSADT, and encouraging to continue further studies.

\section{ACKNOWLEDGEMENTS}

This study was supported by grants from the National Fund for Scientific and Technological Development (FONDECYT 1130320 FS-O, 1130324 MNL and 3090044 LS), the Fund for the Promotion of Scientific and Technological Development (FONDEF DO5I10366 and D11I1036 FS-O and MNL) and the Millennium Science Initiative from the Ministry for the Economy, Development and Tourism (P09/016-F). DR was supported by fellowships 21061192 and 24100211 of the National Commission for Scientific and Technological Research (CONICYT).

\section{CONFLICT OF INTEREST}

The authors declare no conflict of interest.

\section{REFERENCES}

Aguilera R, Saffie C, Tittarelli A, González FE, Ramírez M, Reyes D, Pereda C, Hevia D, García T, Salazar L, Ferreira A, Hermoso M, Mendoza-Naranjo A, Ferrada C, Garrido P, López MN, Salazar-Onfray F (2011) Heat-shock induction of tumor-derived danger signals mediates rapid monocyte differentiation into clinically effective dendritic cells. Clin Cancer Res 17: 2474-2483.

Arancibia S, Del Campo M, Nova E, Salazar F, Becker MI (2012) Enhanced structural stability of Concholepas hemocyanin increases its immunogenicity and maintains its non-specific immunostimulatory effects. Eur J Immunol 42: 688-699.

Banchereau J, Paczesny S, Blanco P, Bennett L, Pascual V, Fay J, Palucka AK (2003) Dendritic cells: controllers of the immune system and a new promise for immunotherapy. Ann NY Acad Sci 987: 180-187.

Bracci L, Schiavoni G, Sistigu A, Belardelli F (2013) Immune-based mechanisms of cytotoxic chemotherapy: implications for the design of novel and rationale-based combined treatments against cancer. Cell Death Differ; e-pub ahead of print 21 June 2013; doi:10.1038/cdd.2013.67.
Chiang CL, Kandalaft LE, Coukos G (2011) Adjuvants for enhancing the immunogenicity of whole tumor cell vaccines. Int Rev Immunol 30: 150-182.

De Ioannes P, Moltedo B, Oliva HH, Pacheco R, De Ioannes AE, Becker MI (2004) Hemocyanin of the molluscan Concholepas concholepas exhibits an unusual heterodecameric array of subunits. J Biol Chem 279: 26134-26142.

Del Campo M, Arancibia S, Nova E, Salazar F, Gonzalez A, Moltedo B, De Ioannes P, Ferreira J, Manubens A, Becker MI (2011) [Hemocyanins as immunostimulants]. Rev Med Chil 139: 236-246.

deVries IJ, Bernsen MR, Lesterhuis WJ, Scharenborg NM, Strijk SP, Gerritsen MJ, Ruiter DJ, Figdor CG, Punt CJ, Adema GJ (2005) Immunomonitoringtumor-specific $\mathrm{T}$ cells in delayed-type hypersensitivity skin biopsies after dendritic cell vaccination correlates with clinical outcome. J Clin Oncol 23: 5779-5787.

Durán-Aniotz C, Segal G, Salazar L, Pereda C, Falcón C, Tempio F, Aguilera R, González R, Pérez C, Tittarelli A, Catalán D, Nervi B, Larrondo M, Salazar-Onfray F, López MN (2013) The immunological response and post-treatment survival of DC-vaccinated melanoma patients are associated with increased Th1/Th17 and reduced Th3 cytokine responses. Cancer Immunol Immunother 62(4): 761-772.

Escobar A, López M, Serrano A, Ramirez M, Pérez C, Aguirre A, González R, Alfaro J, Larrondo M, Fodor M, Ferrada C, Salazar-Onfray F (2005) Dendritic cell immunizations alone or combined with low doses of interleukin-2 induce specific immune responses in melanoma patients. Clin Exp Immunol 142: 555-568.

Fuessel S, Meye A, Schmitz M, Zastrow S, Linné C, Richter K, Löbel B, Hakenberg OW, Hoelig K, Rieber EP, Wirth MP (2006) Vaccination of hormone-refractory prostate cancer patients with peptide cocktail-loaded dendritic cells: results of a phase I clinical trial. Prostate 66: 811-821.

Gathuru JK, Koide F, Ragupathi G, Adams JL, Kerns RT, Coleman TP, Livingston PO (2005) Identification of DHBcAg as a potent carrier protein comparable to KLH for augmenting MUC1 antigenicity. Vaccine 23(39): 4727-4733.

Hart DN (1997) Dendritic cells: unique leukocyte populations which control the primary immune response. Blood 90: 3245-3287.

Hodi FS, O’Day SJ, McDermott DF, Weber RW, Sosman JA, Haanen JB, Gonzalez R, Robert C, Schadendorf D, Hassel JC, Akerley W, van den Eertwegh AJ, Lutzky J, Lorigan P, Vaubel JM, Linette GP, Hogg D, Ottensmeier CH, Lebbé C, Peschel C, Quirt I, Clark JI, Wolchok JD, Weber JS, Tian J, Yellin MJ, Nichol GM, Hoos A, Urba WJ (2010) Improved survival with ipilimumab in patients with metastatic melanoma. $N$ Engl J Med 363(8): 711-723.

Huggins C, Hodges CV (2002) Studies on prostatic cancer: I. The effect of castration, of estrogen and of androgen injection on serum phosphatases in metastatic carcinoma of the prostate 1941. J Urol 168: 9-12.

Idakieva K, Nikolov P, Chakarska I, Genov N, Shnyrov VL (2008) Spectroscopic properties and conformational stability of Concholepas concholepashemocyanin. J Fluoresc 18(3): 715-725.

Jemal A, Siegel R, Ward E, Hao Y, Xu J, Thun MJ (2009) Cancer statistics (2009). CA Cancer J Clin 59: 225-249.

Joffre O, Nolte MA, Spörri R, Reis e Sousa C (2009) Inflammatory signals in dendritic cell activation and the induction of adaptive immunity. Immunol Rev 227: 234-247.

Kantoff PW, Higano CS, Shore ND, Berger ER, Small EJ, Penson DF, Redfern CH, Ferrari AC, Dreicer R, Sims RB, Xu Y, Frohlich MW, Schellhammer PF, IMPACT Study Investigators (2010) Sipuleucel-T immunotherapy for castration-resistant prostate cancer. N Engl J Med 363: 411-422.

Klebanoff CA, Gattinoni L, Restifo NP (2006) CD8 + T-cell memory in tumor immunology and immunotherapy. Immunol Rev 211: 214-224.

Kobayashi K, Kaneda K, Kasama T (2001) Immunopathogenesis of delayedtype hypersensitivity. Microsc Res Tech 53: 241-245.

Liu Q, Wang Y, Wang H, Liu Y, Liu T, Kunda PE (2013) Tandem therapy for retinoblastoma: immunotherapy and chemotherapy enhance cytotoxicity on retinoblastoma by increasing apoptosis. J Cancer Res Clin Oncol 139(8): $1357-1372$.

López M, Aguilera R, Pérez C, Mendoza-Naranjo A, Pereda C, Ramirez M, Ferrada C, Aguillón JC, Salazar-Onfray F (2006) The role of regulatory T lymphocytes in the induced immune response mediated by biological vaccines. Immunobiology 211: 127-136.

López MN, Pereda C, Segal G, Muñoz L, Aguilera R, González FE, Escobar A, Ginesta A, Reyes D, González R, Mendoza-Naranjo A, Larrondo M, Compán A, Ferrada C, Salazar-Onfray F (2009) Prolonged survival of 
dendritic cell-vaccinated melanoma patients correlates with tumor-specific delayed type IV hypersensitivity response and reduction of tumor growth factor beta-expressing T cells. J Clin Oncol 27: 945-952.

Ma Y, Adjemian S, Mattarollo SR, Yamazaki T, Aymeric L, Yang H, Portela Catani JP, Hannani D, Duret H, Steegh K, Martins I, Schlemmer F, Michaud M, Kepp O, Sukkurwala AQ, Menger L, Vacchelli E, Droin N, Galluzzi L, Krzysiek R, Gordon S, Taylor PR, Van Endert P, Solary E, Smyth MJ, Zitvogel L, Kroemer G (2013) Anticancer chemotherapyinduced intratumoral recruitment and differentiation of antigenpresenting cells. Immunity 38(4): 729-741.

Moltedo B, Faunes F, Haussmann D, De Ioannes P, De Ioannes AE, Puente J, Becker MI (2006) Immunotherapeutic effect of Concholepashemocyanin in the murine bladder cancer model: evidence for conserved antitumor properties among hemocyanins. J Urol 176: 2690-2695.

Mottet N, Bellmunt J, Bolla M, Joniau S, Mason M, Matveev V, Schmid HP, Van der Kwast T, Wiegel T, Zattoni F, Heidenreich A (2011) EAU guidelines on prostate cancer. Part II: treatment of advanced, relapsing, and castration-resistant prostate cancer. Eur Urol 59: 572-583.

Mu LJ, Kyte JA, Kvalheim G, Aamdal S, Dueland S, Hauser M, Hammerstad H, Waehre H, Raabe N, Gaudernack G (2005) Immunotherapy with allotumour mRNA-transfected dendritic cells in androgen-resistant prostate cancer patients. Br J Cancer 93: 749-756.

Pagès F, Kirilovsky A, Mlecnik B, Asslaber M, Tosolini M, Bindea G, Lagorce C, Wind P, Marliot F, Bruneval P, Zatloukal K, Trajanoski Z, Berger A, Fridman WH, Galon J (2009) In situ cytotoxic and memory $\mathrm{T}$ cells predict outcome in patients with early-stage colorectal cancer. J Clin Oncol 27: 5944-5951.

Pandha HS, John RJ, Hutchinson J, James N, Whelan M, Corbishley C, Dalgleish AG (2004) Dendritic cell immunotherapy for urological cancers using cryopreserved allogeneic tumor lysate-pulsed cells: a phase I/II study. BJU Int 94: 412-418.

Petrylak DP, Tangen CM, Hussain MH, Lara Jr PN, Jones JA, Taplin ME, Burch PA, Berry D, Moinpour C, Kohli M, Benson MC, Small EJ, Raghavan D, Crawford ED (2004) Docetaxel and estramustine compared with mitoxantrone and prednisone for advanced refractory prostate cancer. N Engl J Med 351: 1513-1520.

Pienta KJ, Bradley D (2006) Mechanisms underlying the development of androgen-independent prostate cancer. Clin Cancer Res 12: 1665-1671.
Semeniuk RC, Venner PM, North S (2006) Prostate-specific antigen doubling time is associated with survival in men with hormone-refractory prostate cancer. Urology 68: 565-569.

Shedlock DJ, Shen H (2003) Requirement for CD4 T cell help in generating functional CD8 T cell memory. Science 300: 337-339.

Shoemaker LK, Estfan B, Induru R, Walsh TD (2011) Symptom management: an important part of cancer care. Cleve Clin J Med 78: 25-34.

Sullivan PW, Mulani PM, Fishman M, Sleep D (2007) Quality of life findings from a multicenter, multinational, observational study of patients with metastatic hormone-refractory prostate cancer. Qual Life Res 16: 571-575.

Tannock IF, de Wit R, Berry WR, Horti J, Pluzanska A, Chi KN, Oudard S, Théodore C, James ND, Turesson I, Rosenthal MA, Eisenberger MA. TAX 327 Investigators (2004) Docetaxel plus prednisone or mitoxantrone plus prednisone for advanced prostate cancer. N Engl J Med 351: 1502-1512.

Tittarelli A, González FE, Pereda C, Mora G, Muñoz L, Saffie C, García T, Díaz D, Falcón C, Hermoso M, López MN, Salazar-Onfray F (2012) Tolllike receptor 4 gene polymorphism influences dendritic cell in vitro function and clinical outcomes in vaccinated melanoma patients. Cancer Immunol Immunother 61: 2067-2077.

Tjoa BA, Simmons SJ, Elgamal A, Rogers M, Ragde H, Kenny GM, Troychak MJ, Boynton AL, Murphy GP (1999) Follow-up evaluation of a phase II prostate cancer vaccine trial. Prostate 40: 125-129.

Watcha MF, White PF (1992) Postoperative nausea and vomiting. Its etiology, treatment, and prevention. Anesthesiology 77: 162-184.

Weber J, Hamid O, Amin A, O'Day S, Masson E, Goldberg SM, Williams D, Parker SM, Chasalow SD, Alaparthy S, Wolchok JD (2013) Randomized phase I pharmacokinetic study of ipilimumab with or without one of two different chemotherapy regimens in patients with untreated advanced melanoma. Cancer Immun 13: 7.

Wolchok JD, Kluger H, Callahan MK, Postow MA, Rizvi NA, Lesokhin AM, Segal NH, Ariyan CE, Gordon RA, Reed K, Burke MM, Caldwell A, Kronenberg SA, Agunwamba BU, Zhang X, Lowy I, Inzunza HD, Feely W, Horak CE, Hong Q, Korman AJ, Wigginton JM, Gupta A, Sznol M (2013) Nivolumab plus Ipilimumab in advanced melanoma. N Engl J Med 369(2): $122-133$.

This work is published under the standard license to publish agreement. After 12 months the work will become freely available and the license terms will switch to a Creative Commons AttributionNonCommercial-Share Alike 3.0 Unported License.

Supplementary Information accompanies this paper on British Journal of Cancer website (http://www.nature.com/bjc) 